\title{
Conservation Tillage and Fertilization Impact on Carbon Sequestration and Mineralization in Soil Aggregates in the North West IGP under an Irrigated Rice-Wheat Rotation: A Review
}

\author{
Shipra Yadav ${ }^{1 *}$, R. K. Naresh ${ }^{1}$, Yogesh Kumar $^{2}$ and R. B. Yadav ${ }^{1}$ \\ ${ }^{1}$ Department of Agronomy, ${ }^{2}$ Department of Soil Science \& Agricultural Chemistry, \\ Sardar Vallabhbhai Patel University of Agriculture \& Technology, Meerut, (UP), India \\ *Corresponding author
}

\section{Keywords}

Conservation tillage, Carbon sequestration, Carbon mineralization, Soil organic carbon

Article Info

Accepted:

08 January 2020

Available Online:

10 February 2020

\section{A B S T R A C T}

Understanding the process of soil organic carbon (SOC) sequestration and mineralization in aggregates is pertinent to mitigate climate change and minimize risks of soil degradation. The NT system increased the proportion of $>2 \mathrm{~mm}$ aggregate fraction and reduced the proportion of $<0.053$ $\mathrm{mm}$ aggregates in both $0.00-0.05$ and $0.05-0.20 \mathrm{~m}$ layers. The SOC concentration, SOC stock and humic and fulvic acids within the $>0.25 \mathrm{~mm}$ macro-aggregate fraction also significantly increased in the $0.00-0.5 \mathrm{~m}$ layer in NT system. However, those within the $2.00-0.25 \mathrm{~mm}$ aggregate fraction were significantly reduced in the $0.05-0.200 \mathrm{~m}$ layer under NT system. Straw incorporation increased not only the SOC stock in bulk soil, but also the proportion of macro-aggregate, aggregate associated with SOC and humic and fulvic acids concentration within the aggregate. Compared to conventional tillage, the percentages of $>2 \mathrm{~mm}$ macro-aggregates and water-stable macro-aggregates in rice-wheat double conservation tillage (zero-tillage and straw incorporation) were increased $17.22 \%$ and $36.38 \%$ in the $0-15 \mathrm{~cm}$ soil layer and $28.93 \%$ and $66.34 \%$ in the $15-30 \mathrm{~cm}$ soil layer, respectively. Furthermore, the large macro-aggregates $(>2 \mathrm{~mm}$ ) with the highest proportion of size distribution represented the major pool of SOC stock $(47.3-51.2 \%)$ and mineralization amount $(38.2-43.6 \%)$ in the $0-30 \mathrm{~cm}$ layer, followed by that in the small macro-aggregates $(0.25-2 \mathrm{~mm})$, regardless of tillage practices. However, the mineralization quotient (mineralization per unit SOC concentration) of macro-aggregates $(>0.25 \mathrm{~mm})$ was lower than that for the other size classes. The NTS enhanced the macro-aggregate formation in the $0-20 \mathrm{~cm}$ layer and associated SOC concentration in the $0-10 \mathrm{~cm}$ layer. Furthermore, NTS decreased total potential mineralization in the $0-30 \mathrm{~cm}$ layer compared with the other tillage practices, attributed to decrease in the large macro-aggregates $(30.0-51.4 \%)$ with low particulate organic carbon (POC) concentration. Zero tillage and straw incorporation also increased the mean weight diameter and stability of the soil aggregate. In surface soil $(0-15 \mathrm{~cm})$, the maximum proportion of total aggregated carbon was retained with $0.25-0.106 \mathrm{~mm}$ aggregates, and rice-wheat double-conservation tillage had the greatest ability to hold the organic carbon $(33.64 \mathrm{~g}$ $\mathrm{kg}^{-1}$ ). In the NPK + FYM treatment, LOC was $\sim 16 \%$ significantly higher in topsoil than the subsurface soil. Aggregate size of $>2000,250-2000,53-250$ and $<53 \mu \mathrm{m}$ had $\sim 18,26,34$ and $18 \%$ higher soil aggregate-associated organic $\mathrm{C}$ in topsoil than $5-15 \mathrm{~cm}$ soil layer, respectively. Decreasing trend of soil aggregate-associated $\mathrm{C}$ was observed with decrease in size fraction from > 2000 to $<53 \mu \mathrm{m}$. Plots with fertilization of $50 \% \mathrm{NPK}+50 \% \mathrm{GM}\left(1.8 \mathrm{t} \mathrm{ha}^{-1}\right)$ had significantly higher total soil organic C (TOC), LOC, macro-aggregate-associated C concentrations, and soil aggregation than other treatments. These collected review demonstrated that conservation agriculture that integrates application of nutrient management, tillage and crop residue is crucial for improving soil health and sustainability of farming systems in Northwest IGP. 


\section{Introduction}

Soil carbon (C) pool is the third largest global $\mathrm{C}$ stock, which is 2 and 2.5 times higher than the atmospheric and terrestrial vegetation $\mathrm{C}$ pools, respectively (Song et al., 2016). Thus, enhancing soil organic C (SOC) sequestration is an effective approach to reduce greenhouse gas (GHG) emissions (Somasundaram et al., 2017). Soil aggregates are vital physical dimensions of soil protection, and nearly $90 \%$ of SOC sequestration occurs in soil aggregates (Sarker et al., 2018b). Each aggregate size class contains SOC with different degrees of physical protection against microbial decomposition by encapsulation as affected by management practices. It is known that SOC accumulation and sequestration depend on the $\mathrm{C}$ input sourced from crop straw and its mineralization by soil microbes (Xie et al., 2017). Thus, evaluating SOC mineralization and stabilization in aggregates is key to understand the mechanisms of long-term SOC sequestration (Rabbi et al., 2014). The application of compost significantly increased the amount of mineral-associated organic carbon (MOC) within macro-aggregates through a biochemical protection mechanism. However, the application of mineral fertilizer (NPK) mainly enhanced the amount of $\mathrm{C}$ in the intra-micro-aggregate particulate organic carbon (iPOC) fraction within macroaggregates in an Aquic Inceptisol by a physical protection mechanism. Understanding the mechanisms of SOC sequestration and their responses to different fertilization regimes might therefore be of value in establishing suitable field management strategies for a given soil to deliver 'win-win' benefits in terms of improvement in both soil fertility and climate change mitigation.

Tillage practices may also influence the distribution pattern of soil organic carbon
(SOC). It was observed higher SOC concentration in the surface layers in no tillage than conventional tillage practice, but a higher concentration of SOC in the deeper soil layers of reduce tilled plots where crop stubbles are incorporated through tillage (Gal et al., 2007). Conservation tillage practices are an operative management practices to increase SOC (Wang et al., 2014). Conversely, other studies have reported that no tillage without crop residue resulted in lesser or no change in SOC (Govaerts et al., 2009; Sainju et al., 2008). The review studies present the nutrient, crop residue and tillage management on carbon sequestration and mineralization in soil aggregates and to explain the relationship between different SOC fractions and SOC concentrations and (i) increases the proportion of macro-aggregates (>0.25 mm), (ii) enhances $C$ concentration in macro-aggregates, and (iii) decreases total $\mathrm{C}$ mineralization due to the lower contribution of macro-aggregates. Thus, the objectives were to: (i) evaluate the different mineralization dynamics and cumulative $\mathrm{C}$ loss in aggregates under different tillage practices, and (ii) provide a scientific basis for an appropriate tillage system and fertilization in the Northwest IGP. Improved understanding of labile organic matter fractions will provide valuable information for establishing sustainable fertilizer management systems to maintain and enhance soil quality.

\section{Aggregate size distribution}

Soil aggregate fractions are arranged into their individual primary particles such as sand, silt and clay and arrangement of the aggregates within the soil mass together within the pore size distribution. ... They proposed the boundary between microaggregates and macro-aggregate to be $0.25 \mathrm{~mm}$ of aggregate diameter. Bandyopadhyay et al., (2010) also reported 
that long term application of NPK only resulted in a decrease in micro-aggregates, maintaining a similar MWD as compared with control treatment at a soil depth of 0-15 $\mathrm{cm}$, but that it had no effects at 15-30 and 30$45 \mathrm{~cm}$ depths in an Inceptisol. On a sandy loam with an initial SOC content of $4.8 \mathrm{~g}$ $\mathrm{kg}^{-1}$, increases in soil aggregation were observed after 7 years of incorporation of rice straw (Benbi and Senapati, 2010) .Fang et al., (2015) also found that the mass of soil aggregates of $>5 \mathrm{~mm}$ diameter was the greatest followed by $2-5 \mathrm{~mm}, 0.5-1 \mathrm{~mm}$, $0.25-0.5 \mathrm{~mm}$, and $<0.25 \mathrm{~mm}$, and that of $1-2$ $\mathrm{mm}$ aggregates was the lowest. Moreover, smaller aggregates had a higher OC concentration $(0.5-1 \mathrm{~mm}, 0.25-0.5 \mathrm{~mm}$ and $<0.25 \mathrm{~mm}$ ) than larger aggregates $(>5 \mathrm{~mm}, 2$ $5 \mathrm{~mm}$ and 1-2 $\mathrm{mm}$ ) in CF topsoil, and OC concentration decreased with increasing aggregate size in BF topsoil. In contrast, the OC concentration varied very little between aggregate size classes at deep soil.

Yan et al., (2013) observed that particulate organic $\mathrm{C}$ was found stratified along the soil depth. A higher POC was found in surface soil decreasing with depth. At the $0-20 \mathrm{~cm}$, POC content under NP+FYM, NP+S and FYM were 103, 89 and $90 \%$ greater than under CK, respectively. In 20-40 cm and 40$60 \mathrm{~cm}$ soil layers, NP+FYM had maximum POC which was significantly higher than $\mathrm{NP}+\mathrm{S}$ and FYM treatments. Even though POC below $60 \mathrm{~cm}$ depth was statistically similar among fertilization treatments, the general trend was for increased POC with farmyard manure or straw application down to $100 \mathrm{~cm}$ soil depth. Guo et al., (2016) reported that in the $0-5 \mathrm{~cm}$ soil layer, NT treatments significantly increased SOC concentration by $5.8 \%, 6.8 \%$, and $7.9 \%$ of bulk soil, $>0.25 \mathrm{~mm}$ aggregate, and $<0.25 \mathrm{~mm}$ aggregate, respectively, compared with CT treatments. NT treatments significantly increased MBC of bulk soil, $>0.25 \mathrm{~mm}$ and
$<0.25 \mathrm{~mm}$ aggregates by $11.2 \%, 11.5 \%$ and $20.0 \%$, respectively, compared with CT treatments. DOC concentrations of bulk soil, $>0.25 \mathrm{~mm}$ aggregate, and $<0.25 \mathrm{~mm}$ aggregate under NT treatments were $15.5 \%$, $29.5 \%$, and $14.1 \%$ higher than those under CT treatments, respectively. In comparison with NS treatments, $S$ treatments significantly increased SOC concentrations of bulk soil by $12.8 \%,>0.25 \mathrm{~mm}$ aggregate by $11.3 \%$, and $<0.25 \mathrm{~mm}$ aggregate by $14.1 \%$. In addition, MBC of bulk soil, $>0.25 \mathrm{~mm}$ aggregate, and $<0.25 \mathrm{~mm}$ aggregate under $\mathrm{S}$ treatments were $29.8 \%, 30.2 \%$, and $24.1 \%$ higher than those of NS treatments, respectively. S treatments exhibited $25.0 \%, 37.5 \%$, and $23.2 \%$ higher DOC concentrations of bulk soil, $>0.25 \mathrm{~mm}$ aggregate, and $<0.25 \mathrm{~mm}$ aggregate compared with NS treatments, respectively. In the 0-5 $\mathrm{cm}$ soil layer, there were significant interactions of tillage and straw returning on SOC concentration of $>0.25 \mathrm{~mm}$ and $<0.25$ $\mathrm{mm}$ aggregates, $\mathrm{MBC}$ of bulk soil and $<0.25$ $\mathrm{mm}$ aggregate, and DOC concentration of $>0.25 \mathrm{~mm}$ aggregate. Conservation tillage significantly increased SOC concentration of bulk soil in the $0-5 \mathrm{~cm}$ soil layer. This increase in SOC concentration can be attributed to a combination of less soil disturbance and more residues returned to the soil surface under conservation tillage (Du et al., 2010). Triberti et al., (2008) reported that crop residues can significantly increase SOC concentration.

Duan et al., (2015) concluded that the SOC distribution in various aggregate size fractions. The first 60-days incubation increased SOC content by $\sim 100 \%$ in the $>2000 \mathrm{~mm}$ fraction, $50 \%$ in the whole soil and $2000-250 \mu \mathrm{m}$ fraction, and $\sim 20 \%$ in the $<53 \mathrm{~mm}$ fractions. But significant increase was not observed for 250-53 $\mu \mathrm{m}$ microaggregate fraction. After then, the SOC content in the $>250 \mathrm{~mm}$ fractions (especially the $>2000 \mathrm{~mm}$ fraction) decreased due to 
strong decomposition of added residue organic matter through respiration but it remained stable in the whole soil, $250-53 \mu \mathrm{m}$ fraction, and $<53 \mathrm{~mm}$ fraction. After one year, the $>2000 \mathrm{~mm}$ fraction had the highest SOC content, an increase by $35 \%$ relative to its original level. The whole soil and 2000-250 $\mu \mathrm{m}$ fraction contained the second most SOC, representing a $\sim 40 \%$ increase from their original levels. The SOC content in the 250 $53 \mu \mathrm{m}$ fraction started to increase half year after the initiation of incubation, showing an increase of $\sim 20 \%$ on day 360 relative to its original level.

Hui-Ping Ou et al., (2016) reported that the average humic and fulvic acids concentrations for all the aggregate size fractions was $43.9 \%$ higher in NT-S than in MP-S, and $20.5 \%$ higher in $\mathrm{NT}+\mathrm{S}$ than in $\mathrm{MP}+\mathrm{S}$ in the 0.00 $0.05 \mathrm{~m}$ layer. However, an opposite trend was observed in the $0.05-0.20$ and $0.20-0.30 \mathrm{~m}$ layers. For all the soil layers, the humic and fulvic acids concentrations in all the aggregate size fractions was increased with straw incorporation, by $36.5,33.3$ and $46.8 \%$ in the $0.00-0.05,0.05-0.20$ and $0.20-0.30 \mathrm{~m}$ layers for the MP system, respectively, while 14.2,32.1 and $24.7 \%$, respectively, for the NT system. When compared to MP+S,NT-S only significantly increased the humic and fulvic acids concentrations in the $2.00-0.25 \mathrm{~mm}$ aggregate fraction in the $0.00-0.05 \mathrm{~m}$ layer, but decreased it in all the aggregate fractions in the $0.05-0.20$ and $0.20-0.30 \mathrm{~m}$ layer.

Naresh et al., (2016) also found significantly higher POC content was probably also due to higher biomass C. Results on PON content after 3-year showed that in $0-5 \mathrm{~cm}$ soil layer of CT system, $\mathrm{T}_{1}$, and T5treatments increased PON content from $35.8 \mathrm{mgkg}-1$ in CT (T9) to 47.3 and $67.7 \mathrm{mg} \cdot \mathrm{kg}-1$ without $\mathrm{CR}$, and to78.3, 92.4 and $103.8 \mathrm{mgkg}^{-1}$ with CR @ 2, 4and 6 tha $^{-1}$, respectively. The corresponding increase of PON content under CA system was from 35.9 mgkg-1in CT systems to 49 and $69.6 \mathrm{mgkg}^{-1}$ without $\mathrm{CR}$ and 79.3, 93.0 and $104.3 \mathrm{mgkg}^{-1}$ with CR @ 2, 4 and 6 tha $^{-1}$, respectively. Small improvement in PON content was observed after 4 years of the experiment. Singh et al., (2014) found that carbon stock of $18.75,19.84$ and $23.83 \mathrm{Mg}^{-}$ ${ }^{1}$ in the surface $0.4 \mathrm{~m}$ soil depth observed under CT was increased to 22.32, 26.73 and $33.07 \mathrm{Mg} \mathrm{ha}{ }^{-1}$ in 15 years of ZT in sandy loam, loam and clay loam soil. This increase was highest in clay loam (38.8\%) followed by loam $(34.7 \%)$ and sandy loam (19.0\%) soil. The carbon sequestration rate was found to be $0.24,0.46$ and $0.62 \mathrm{Mg} \mathrm{ha}^{-1} \mathrm{yr}^{-1}$ in sandy loam, loam and clay loam soil under ZT over CT. Thus, fine textured soils have more potential for storing carbon and ZT practice enhances carbon sequestration rate in soils by providing better conditions in terms of moisture and temperature for higher biomass production and reduced oxidation (Gonzalez-Sanchez et al., 2012).

Xie et al., (2018) revealed that the largest percentage, which ranged from 52.0 to $60.7 \%$ at a depth of $0-10 \mathrm{~cm}$ and from 63.2 to $73.4 \%$ at $10-20-\mathrm{cm}$ depth, followed by microaggregates occluded in the macro-aggregate fraction (24.5-34.6 and 21.0-28.9\%, respectively). The cPOC fraction had the smallest percentage (11.0-17.0\% and 5.5$10.0 \%$, respectively) at the two soil depths for all treatments. Within the micro-aggregate occluded in macro-aggregate fraction, the mass proportion of the $\mathrm{s}+\mathrm{c} \_\mathrm{m}$ fraction was the largest $(10.2-27.5 \%$ at a depth of $0-10 \mathrm{~cm}$ and $11.9-19.8 \%$ at $10-20 \mathrm{~cm}$ ), followed by the iPOC fraction (6.3-13.6 and 7.5-11.5\%, respectively), and the smallest fraction was fPOC, with only $0.3-2.1 \%$ at $0-10 \mathrm{~cm}$ and $0.2-0.4 \%$ at $10-20 \mathrm{~cm}$. Kan et al., (2020) also found that the macro-aggregates size classes were the most abundant for all tillage practices throughout the $0-50 \mathrm{~cm}$ layer, accounting for $52.9 \%$ (CT)-59.1\% (NTS) in 
the $\mathrm{LM}>2$ size class and $24.6 \%$ (CT) $-28.0 \%$ (NTS) in the SM0.25-2 size class. In the LM>2 size class, the highest value was observed under NTS, higher than CT (lowest) by $40.7,35.0$, and $20.3 \%$ at $0-5,5-10$, and 10-20 cm layers, respectively.

\section{Aggregate-associated C}

Zhu et al., (2014) observed that the contents of soil TOC and labile organic $\mathrm{C}$ fractions, where PD generally had the highest contents of TOC, DOC, MBC and EOC at the three soil depths. Crop straw return treatments (PR, PW, PD, RR, RW, RD) had consistently higher amount of TOC and labile organic $\mathrm{C}$ fractions at the three soil depths than without crop straw return treatments $(\mathrm{PN}, \mathrm{RN})$. Moreover, PN had significantly lower TOC, DOC, MBC and EOC at $0-7 \mathrm{~cm}$ and 7-14 $\mathrm{cm}$, and RN had the lowest TOC and MBC at 14-21 cm compared to other treatments. Soil TOC and labile organic $\mathrm{C}$ fractions generally decreased with an increase in soil depth under all treatments. The reason could be attributed to the tillage method. Tillage increases the effect of drying- rewetting and freezingthawing on soil, which increases macroaggregate susceptibility to disruption (Beare et al., 1994) and accelerates the labile organic $\mathrm{C}$ mineralization and SOM degradation, thus increasing the loss of EOC.

Awanish, (2016) reported that the greater variations among carbon fractions were observed at surface layer $(0-5 \mathrm{~cm}) \cdot \mathrm{F}_{1}=$ very labile, $\mathrm{F}_{2}=$ labile, $\mathrm{F}_{3}=$ less labile and, $\mathrm{F}_{4}=$ nonlabile. At this depth, $\mathrm{C}$ fraction in vertisols varied in this order: $F_{4}>F_{1}>F_{2}=F_{3}$. Below 5 $\mathrm{cm}$, the carbon fraction was in the order: $F_{4}>F_{1}>F_{3}>F_{2}$. For $15-30 \mathrm{~cm}$ depth it was in the order $F_{4}>F_{1}>F_{2}>F_{3}$. At lower depth, almost similar trend was followed as that of $30-45 \mathrm{~cm}$. Regardless of tillage system, contribution of different fractions of carbon (C) to the TOC varied from, 33 to $41 \% ; 9.30$ to $30.11 \% ; 8.11$ to $26 \% ; 30.6$ to $45.20 \%$ for very labile, labile, less labile and non-labile fractions, respectively at $0-5 \mathrm{~cm}$ depth. For subsurface layer $(5-15 \mathrm{~cm})$, contribution of different fractions to the TOC varied from 27.8 to $40 \% ; 7.80$ to $12.40 \% ; 11.11$ to $19.0 \%$; 38.0 to $50.0 \%$ for very labile, labile, less labile and non-labile fraction, respectively. In general, $\mathrm{C}$ contents decreased with increasing depth, mainly for very labile faction $\left(\mathrm{F}_{1}\right)$ which was contributing around $40 \%$ or more in surface and surface layers (0-5 and 5-15 $\mathrm{cm})$ as compared to deeper layers(15-30 and $30-45 \mathrm{~cm})$. Moreover, less labile and nonlabile fractions contribute more than $50 \%$ of TOC, indicating more recalcitrant form of carbon in the soil.

Ou et al., (2016) reported that the tillage systems obviously affected the distribution of soil aggregates with different sizes. The proportion of the $>2 \mathrm{~mm}$ aggregate fraction in $\mathrm{NT}+\mathrm{S}$ was $7.1 \%$ higher than that in NT-S in the $0.00-0.05 \mathrm{~m}$ layer. There was no significant difference in the total amount of all the aggregate fractions between $\mathrm{NT}+\mathrm{S}$ and NT-S in both the 0.05-0.20 and 0.20-0.30 m layers. $\mathrm{NT}+\mathrm{S}$ and NT-S showed higher proportions of $>2 \mathrm{~mm}$ aggregate and lower proportions of $<0.053 \mathrm{~mm}$ aggregate compared to the MP system for the 0.00-0.20 $\mathrm{m}$ layer. The proportion of $>0.25 \mathrm{~mm}$ macroaggregate was significantly higher in $\mathrm{MP}+\mathrm{S}$ than in MP-S in most cases, but the proportion of $<0.053 \mathrm{~mm}$ aggregate was 11.5 $20.5 \%$ lower in $\mathrm{MP}+\mathrm{S}$ than in MP-S for all the soil layers. Du et al., (2013) reported that the NT system did affect the SOC stock distribution in the soil profile but not the total quantity. Tillage regimes obviously influenced soil aggregation distribution in the soil profile. In the upper $0.00-0.05$ and 0.05 $0.20 \mathrm{~m}$ layers, the NT system improved the formation level of the $>2 \mathrm{~mm}$ aggregate but reduced the formation level of $<0.053 \mathrm{~mm}$ aggregates, compared to the MP system, 
suggesting that mechanical operation reduced large-macro-aggregate formation and disrupted soil macro-aggregates into individual particles (Huang et al., 2010 and Jiang et al., 2011).

The aggregate-associated SOC concentration in different soil layers was influenced by tillage systems. In the 0.00-0.05 m layer, SOC concentration in macro-aggregates showed the order of $\mathrm{NT}+\mathrm{S}>\mathrm{MP}+\mathrm{S}=\mathrm{NT}-\mathrm{S}>\mathrm{MP}-\mathrm{S}$, whereas the NT system was superior to the MP system. However, the NT system significantly reduced the SOC concentration in the $2.00-0.25 \mathrm{~mm}$ fraction in the $0.05-0.20$ $\mathrm{m}$ layer. A similar trend was observed in the $0.25-0.053 \mathrm{~mm}$ fraction in the $0.20-0.30 \mathrm{~m}$ layer. Across all the soil layers, there was no difference in the $<0.053 \mathrm{~mm}$ fraction between NT-S and MP-S, as well as between NT+S and $\mathrm{MP}+\mathrm{S}$, indicating that the NT system did not affect the SOC concentration in the silt + clay fraction. In average across the soil layers, the SOC concentration in the macro-aggregate was increased by $13.5 \%$ in $\mathrm{MP}+\mathrm{S}, 4.4 \%$ in NT-S and $19.3 \%$ in NT+S, and those in the micro-aggregate $(<0.25 \mathrm{~mm})$ were increased by $6.1 \%$ in $\mathrm{MP}+\mathrm{S}$ and $7.0 \%$ in $\mathrm{NT}+\mathrm{S}$ compared to MP-S. For all the soil layers, the SOC concentration in all the aggregate size classes was increased with straw incorporation, by 20.0, 3.8 and $5.7 \%$ under the MP system, and 20.2, 6.3 and $8.8 \%$ under the NT system. The higher proportion of $>2$ $\mathrm{mm}$ aggregates and lower proportion of $<0.053 \mathrm{~mm}$ aggregates under NT systems might be the result of the higher soil hydrophobicity, low intensity of wetting and drying cycles, higher soil $\mathrm{C}$ concentration or the physical and chemical characteristics of large macro-aggregates making them more resistant to breaking up (Vogelmann et al., 2013).

Naresh et al., (2017) revealed that out of the four $\mathrm{C}$ fractions, $\mathrm{LFOC}$ and $\mathrm{KMnO}_{4} \mathrm{C}$ were the most sensitive indicators of changes in TOC induced by the soil tillage and nutrient management practices. Under RWCS, TOC contents were similar in $F_{6}, F_{7}$ and $F_{3}$ plots, and significantly higher than those in $\mathrm{F}_{1}$ plots (by $50.4 \% 48.3 \%$, and $43.3 \%$ respectively). Manure addition further enhanced TOC contents, which were highest following the $\mathrm{F}_{5}$ treatment $\left(21.37 \mathrm{gkg}^{-1}\right)$. LFOC were also significantly higher following the treatments including organic amendment than following applications solely of chemical fertilizers, except that the $F_{5}, F_{6}$ and $F_{7}$ treatments resulted in similar LFOC contents. Application solely of chemical fertilizers had no significant effects on LFOC and $\mathrm{KMnO}_{4} \mathrm{C}$ fractions compared with unfertilized control plots. Nevertheless, application of $F_{5}$ or $F_{6}$ significantly increased contents of POC and MBC relative to $F_{1}$ (by $49.6 \%$ and $40.9 \%$ or70.2\% and $63.4 \%$, respectively. Kan et al., (2020) observed that the SOC concentration in aggregates decreased with increase in soil depths, with the highest concentration in the $0-5 \mathrm{~cm}$ layer. In the $0-5 \mathrm{~cm}$ layer, SOC concentration differed significantly among different tillage practices, with the highest value observed in NTS and the lowest in CT; a similar pattern was observed for the 5-10 $\mathrm{cm}$ layer. Macro-aggregates were destroyed to $\sim 15-20 \mathrm{~cm}$ under CTS and CT, and to $\sim 10 \mathrm{~cm}$ under RTS. Tillage causes water loss in the sub-soil layers and decreases earthworm biomass and density by physical injury (Arai et al., 2018), potentially resulting in a degraded sub-soil structure. Increase in macro-aggregates under NTS protected the labile $C$ from microbial attack by encapsulation, and labile $\mathrm{C}$ improved soil aggregate stabilization in return (Six et al., 2002). Thus, the disruption of macroaggregates has adverse impacts on the labile $\mathrm{C}$ pool due to decline in the physical protection, which results in $\mathrm{C}$ loss (Somasundaram et al., 2018). 


\section{SOC stock}

The carbon (C) stored in soils is the largest terrestrial $\mathrm{C}$ pool on earth, with more $\mathrm{C}$ stored in soils than in the atmosphere and living biomass together. Most of soil $\mathrm{C}$ is stored in the form of soil organic matter which originates from decomposition of dead biomass and is incorporated into soils during their evolution. As the $\mathrm{C}$ fixed in soil organic carbon (SOC) partly has relatively short residence times, soils are an important reservoir for carbon exchange between terrestrial ecosystems and the atmosphere at global and regional scale (Lal, 2008). Dameni et al., (2010) also found that the distribution of the SOC contents in aggregate-size fractions at depths of $0-10$ and $10-20 \mathrm{~cm}$ within the profile under various land-use types indicated a significant effect of land use and soil depth on the SOC stock. Within each size class, aggregate $\mathrm{C}$ concentration in the FTL soil was significantly greater than in the CL and GL. For each system, differences generally narrowed with increasing soil depth. For FTL soil, a marked decrease in SOC stock from the first to the second layer was noted. In general, the measured SOC stock across land use types was greater in the topsoil (0-10 $\mathrm{cm})$ than in lower depths. Multiple comparisons of means revealed that at the depth of $0-10 \mathrm{~cm}$, the concentration of SOC in different land-use types followed the order $\mathrm{FTL}>\mathrm{GL} \approx \mathrm{CL}$ for all aggregate-size fractions.

Awale et al., (2013) revealed that compared with CT, ST and NT had significantly higher SOC concentration by 3.8 and $2.7 \%$, SOC stock by $7.2 \%$ and $9.2 \%$, CPOM-C by 22 and $25 \%$, and $\mathrm{KMnO}_{4}-\mathrm{C}$ by 4.8 and $4.1 \%$, respectively. Venkanna et al., (2014) also found that the SOC stocks ranges from 22.68 to $94.83 \mathrm{Mg} \mathrm{ha}^{-1}$ with a mean of $52.84 \mathrm{Mg}$ $\mathrm{ha}^{-1}$ in Alfisols, 34.37 to $73.67 \mathrm{Mg} \mathrm{ha}^{-1}$ with a mean of 51.26 in Inceptisols and 27.80 to 74.20 $\mathrm{Mg} \mathrm{ha}^{-1}$ with a mean of $49.33 \mathrm{Mg} \mathrm{ha}^{-1}$ in case of Vertisols and associated soils. The SIC ranges from 4.14 to $25.54 \mathrm{Mg} \mathrm{ha}^{-1}$ with a mean of $12.39 \mathrm{Mg} \mathrm{ha}^{-1}$ in Alfisols, 7.23 to $34.17 \mathrm{Mg} \mathrm{ha}^{-1}$ with a mean of $17.47 \mathrm{Mg} \mathrm{ha}^{-1}$ in Inceptisols and 9.08 to $71.78 \mathrm{Mg} \mathrm{ha}^{-1}$ with a mean of $22.93 \mathrm{Mg} \mathrm{ha}^{-1}$ in Vertisols and Vertic intergrade. In most of the cases, surface SOC is greater than deeper layers, whereas the reverse trend is observed for SIC in most of the cases. Total carbon stock ranges from 30.81 to $116.42 \mathrm{Mg} \mathrm{ha}^{-1}$ (mean 65.24 $\mathrm{Mg} \mathrm{ha}^{-1}$ ) in Alfisols, 43.12 to 107.20 $\mathrm{Mg} \mathrm{ha}^{-1}$ (mean 68.73 $\mathrm{Mg} \mathrm{ha}^{-1}$ ) in Inceptisols and 39.39 to $145.98 \mathrm{Mg} \mathrm{ha}^{-1}$ (mean $72.26 \mathrm{Mg}$ $\mathrm{ha}^{-1}$ ) in Vertisols and associated soils. Ratio of organic to total carbon stock is maximum in Alfisols followed by Inceptisols and Vertisols.

Mazumdar et al., (2015) revealed that Concentration of $\mathrm{C}$ was higher in macroaggregates as compared to micro-aggregates. Irrespective of treatments, $\mathrm{C}$ concentration was highest in $1-2 \mathrm{~mm}$ followed by $0.5-1 \mathrm{~mm}$ size of macro-aggregates and the concentration decreased as the aggregates became smaller in size. Incorporation of organic manures induces decomposition of organic matter where roots, hyphae and polysaccharides bind mineral particles into micro-aggregates and then these microaggregates bind to form $\mathrm{C}$ rich macroaggregates. Jat et al., (2017) also found that Highest OC was observed under Sc4 $(7.7 \mathrm{~g}$ $\left.\mathrm{kg}^{-1}\right)$ followed by $\mathrm{Sc} 3 \quad\left(7.5 \quad \mathrm{~g} \quad \mathrm{~kg}^{-1}\right)$. Conventional farmers practice ( $\mathrm{Sc} 1)$ showed lowest $\mathrm{OC}\left(4.5 \mathrm{~g} \mathrm{~kg}^{-1}\right)$ at $0-15 \mathrm{~cm}$ soil depth. Highest OC $\left(4.9 \mathrm{~g} \mathrm{~kg}^{-1}\right)$ at $15-30 \mathrm{~cm}$ soil depth was observed under Sc2 compared to others. Compared to other scenarios, OC was 23-27\% higher in Sc 2 at 15-30 cm depth. Higher quantity of residue additions and their slow decomposition due to less soil disturbance might have caused higher $\mathrm{OC}$ and total $\mathrm{N}$ concentrations in the surface layer under Sc3 and Sc4 (Dikgwatlhe et al., 2014). 
Sheng et al., (2015) concluded that the LFOC appeared to be more sensitive to land use changes than SOC both in top and subsoil. MBC stock decline was more pronounced in topsoil (49-86\%) than in subsoil (21-61\%) following land use change. DOC and MBC were the most sensitive indicators to land use change. POC stock cannot be used either as a sensitive indicator of SOC change because it is masked by the insensitive response of the cPOC component. Häring et al., (2017) also found that the continuous manure fertilization in FP plots significantly increased SOC stocks by $0.76 \mathrm{~kg} \mathrm{~m}^{-2}$ per year. Over two years, $\mathrm{C}$ input by manure was $2.4 \mathrm{~kg} \mathrm{~m} \mathrm{~m}^{-2}$. Interestingly, measured SOC increase was only slightly lower than the amount of applied manure-C. After 0.5 years, $89 \%$ and after two years $82 \%$ of the applied manure $\mathrm{C}$ were found in the SOC stocks of FP plots. After 1.5 years, SOC stocks of FP plots exceeded those of BC plots. SOC stocks in control plots were lowest, but slightly increased, similar to BC plots, beyond 0.5 years. Relative to the control, BC plots had only $31 \pm 15 \%$ higher SOC stocks while FP had $64 \pm 19 \%$ higher SOC stocks, after two years. Frequent tillage and the lack of organic fertilization further explain the observed SOC loss.

Samal et al., (2017) reported that full CA recorded significantly higher TOC stock (47.71 $\pm 2.46 \mathrm{Mg} \mathrm{C} \mathrm{ha}^{-1}$ soil) as compared to other scenarios in the total depth of soil studied. On the contrary, S4 (diversified cropping system with high cropping intensity) showed significantly lower C stock (39.33 \pm $2.40 \mathrm{Mg} \mathrm{C} \mathrm{ha}{ }^{-1}$ ) than all other scenarios. On an average, TOC stock in different scenarios follows the order: S3 $(47.71 \pm 2.46)>\mathrm{S} 2$ $(43.91 \pm 0.84)>\mathrm{S} 1(41.65 \pm 0.13)>\mathrm{S} 4$ (39.33 $\pm 2.40 \mathrm{Mg} \mathrm{C}^{-1}$ soil). Maximum accumulation of SOC $(19.41 \pm 1.84 \mathrm{Mg} \mathrm{C}$ $\mathrm{ha}^{-1}$ ) in top depth of soil was observed under S3 followed by S4 $\left(16.56 \pm 1.71 \mathrm{Mg} \mathrm{C}^{-1}\right)$, S2 (16.53 $\left.\pm 0.78 \mathrm{Mg} \mathrm{C} \mathrm{ha}^{-1}\right)$ and S1 (16.22 \pm
$0.60 \mathrm{Mg} \mathrm{C} \mathrm{ha}{ }^{-1}$ ) and SOC accumulation reduced in lower depths. In 10-20 cm depth significantly low SOC was observed in S4 $\left(12.61 \pm 0.10 \mathrm{Mg} \mathrm{C} \mathrm{ha}^{-1}\right)$ and statistically at par values of SOC were obtained in rest scenarios (S1-S3). In 20-30 cm soil depth significantly greater SOC accumulation was recorded in S2 (12.82 $\left.\pm 1.10 \mathrm{Mg} \mathrm{Cha}^{-1}\right)$ and $\mathrm{S} 3\left(13.10 \pm 0.21 \mathrm{Mg} \mathrm{C} \mathrm{ha}^{-1}\right)$ in comparison to S1 $\left(10.36 \pm 1.07 \mathrm{Mg} \mathrm{C} \mathrm{ha}^{-1}\right)$ and S4 (10.16 \pm $\left.0.80 \mathrm{MgC} \mathrm{ha}^{-1}\right)$.

Sapkota et al., (2017) revealed that the effects on SOC stock were significant at $0-0.05$ and $0.05-0.15 \mathrm{~m}$ soil depths only. At $0-0.05 \mathrm{~m}$, ZTDSR-ZTW+R and PBDSR-PBW+R, on an average, had significantly higher SOC stocks, that is 2.4 t/ha more than CTR-CTW. ZTDSR-ZTW, ZTDSR-ZTW+R and PBDSR$\mathrm{PBW}+\mathrm{R}$ had a similar improvement in total SOC at $0.05-0.15 \mathrm{~m}$, which was significantly higher (by about $2.0 \mathrm{t} / \mathrm{ha}$ ) than for CTR-CTW. All the treatments had similar SOC stocks at $0.15-0.3 \mathrm{~m}$ and $0.3-0.6 \mathrm{~m}$ soil depths. Calculations for the whole $0-0.6 \mathrm{~m}$ depth showed that ZTDSR-ZTW+R and PBDSR$\mathrm{PBW}+\mathrm{R}$ contained $5.6 \mathrm{t}$ and $3.9 \mathrm{t} / \mathrm{ha}$ more SOC than CTR-CTW, respectively. The increase in SOC concentration at $0.15 \mathrm{~m}$ soil depth in ZT systems compared with the other treatments could be due to (i) surface retention of crop residues (or stubbles in the case of no residue), (ii) higher plant biomass production (Jat et al., 2014; Naresh et al., 2018) leading to large amounts of root residues left in the system and (iii) a lower rate of organic matter decomposition due to minimum soil disturbance. Higher SOC concentrations in surface soils under ZT compared to CT system have been also reported in the north-western IGP of India by Gupta Choudhury et al., (2014) and were attributed to less disruption of macroaggregates which protected SOC against oxidation. 
Naresh et al., (2018) showed that, soil organic carbon buildup was affected significantly by tillage and residue level in upper depth of 0 $15 \mathrm{~cm}$ but not in lower depth of $15-30 \mathrm{~cm}$. Higher SOC content of $19.44 \mathrm{~g} \mathrm{~kg}^{-1}$ of soil was found in zero tilled residue retained plots followed by $18.53 \mathrm{~g} \mathrm{~kg}^{-1}$ in permanently raised bed with residue retained plots. Whereas, the lowest level of SOC content of $15.86 \mathrm{~g} \mathrm{~kg}^{-1}$ of soil were found in puddled transplanted rice followed by wheat planted under conventionally tilled plots. Kan et al., (2020) reported that the total SOC stock in the 0-30 cm layer increased from $25.2 \mathrm{Mg} \mathrm{ha}^{-1}$ for CT to $36.8 \mathrm{Mg} \mathrm{ha}^{-1}$ for NTS across all four aggregate size classes following the order: NTS > CTS > RTS > CT. There was no significant difference between NTS $(36.8 \mathrm{Mg}$ $\left.\mathrm{ha}^{-1}\right)$ and CTS (36.3 $\left.\mathrm{Mg} \mathrm{ha}{ }^{-1}\right)$. Macroaggregates were the major pool of SOC, accounting for $47.3-51.2 \%$ (large) and 31.3$37.8 \%$ (small) of the total SOC stock, respectively, following the order: NTS $>$ CTS $>$ RTS >CT. Liu et al., (2014) reported that straw incorporation in soil increased SOC stocks more than that by surface mulching. However, the SOC stock was sensitive to the decline in input of straw-C and lower biomass production under NTS, indicating that tillage practices affected the conversion of straw $\mathrm{C}$ input into SOC increment and was higher under NTS compared with that under CTS.

\section{Aggregate-associated SOC mineralization}

Understanding the mechanisms for soil carbon storage and stabilization relative to land management is increasingly relevant as soil organic carbon (SOC) is known to be a major pool of global $\mathrm{C}$ and SOC is critical to sustaining soil productivity. Since physical protection of SOC within stable soil aggregates is considered to be one of the major SOC stabilization mechanisms (Mikutta et al., 2006) the effect of land management on aggregate stability is accepted as a key factor in determining SOC levels (Six et al., 1998). Dey et al., (2016) observed that in the surface $(0-15 \mathrm{~cm})$ soil, $\mathrm{DSR}+\mathrm{BM}-\mathrm{ZTW}, \mathrm{DSR}+\mathrm{BM}-\mathrm{ZTW}+\mathrm{RR}$, MBR+DSR-ZTW-ZTMB and MBR+DSRZTW+RR-ZTMB had 15.6, 31.0, 62.1 and 70.6 per cent more POM-C, respectively compared with TPR-CTW. Compared with DSR-ZTW+RR, POM-C under DSR+BMZTW +RR and MBR+DSR-ZTW+RR-ZTMB was higher by 21.5 and 58.2 per cent, respectively owing to addition of extra biomass in the latter options. Zero tillage only in wheat or addition of rice residue alone did not contribute much to the POM-C compared to conventional practice. Maximum improvement in POM-C was there due to mungbean residue retention compared to others. Among the single residue DSR-ZTW systems, retention of mungbean residue resulted in the highest POM-C, which was 52.7 per cent higher than DSR-ZTW without any residue retention. Out of the two double residue systems, MBR+DSR-ZTW+RRZTMB had 30.2 per cent higher POM-C compared with DSR+BM-ZTW+RR. In the sub-surface soil layer, all treatments had similar POM-C except under MBR+DSRZTW+RR-ZTMB, which registered 23.3 per cent higher POM-C compared with that under TPR-CTW. The DSR+BM-ZTW+RR, MBR+DSR-ZTW-ZTMB and MBR+ DSRZTW+RR-ZTMB had 42.6, 50.4 and 66.5 per cent more POM-N in surface soil as compared to TPR-CTW. Under CA practices, slow macro-aggregate turnover in $\mathrm{ZT}$ allowed time for the formation of POM from recent cropderived organic matter and subsequent encapsulation of this POM by mineral particles and microbial by products to form stable aggregates containing young cropderived $\mathrm{C}$.

Ghosh et al., (2018) observed that the plots with 50\% NPK+ 50\% FYM had significantly higher SOC content followed by $50 \%$ NPK + 
50\% GM in topsoil. Significantly lower bulk SOC was found with control plots in topsoil. Significantly higher (+35 and 38\%) SOC with $50 \%$ NPK $+50 \%$ FYM compared to control in both soil layers, respectively. Similar trend of bulk SOC was observed in the $5-15 \mathrm{~cm}$ soil layer. This increase was found due to significantly increased $\mathrm{C}$ input with organic amendments coupled with mineral fertilization. Build-up of organic carbon is more in surface layer than in lower depth because of more addition of roots and plant biomass in surface layers and lack of nutrient and biological activity in deeper layers, which ultimately constrain the rooting depth. Kan et al., (2020) reported that macro-aggregates were the major pool of mineralized $\mathrm{C}$, accounting for $38.2-43.6 \%$ (large) and 34.6$42.5 \%$ (small) of TPM in the surface $30 \mathrm{~cm}$ layer, respectively. Such a trend can be explained that macro- aggregate size classes were predominately present for all tillage practices throughout the $0-50 \mathrm{~cm}$ layer in the bulk soil, accounting for 52.9-59.1\% (large) and 24.6-28.0\% (small) of size classes. Furthermore, the contribution of the surface layer to total $\mathrm{C}$ mineralization in the $0-30 \mathrm{~cm}$ layers increased with decrease in aggregate size. Such a trend further reflects the feature of aggregate size distribution, namely that the amount of macro-aggregate increases with increase in soil depths. Therefore, the difference in aggregate size distribution is the primary reason for the differences in mineralization per unit soil among the soil layers.

\section{Cumulative and total potentially mineralization}

The SOC fractions, such as dissolved organic $\mathrm{C}$ (DOC) and microbial biomass $\mathrm{C}$ (MBC) and particulate are considered to be more sensitive indicators of treatment induced changes than the total SOC (Dong et al., 2009). Chen et al., (2009) reported that labile organic $\mathrm{C}$ fractions are sensitive to SOC changes, with sensitivities decreasing in the order of POC $>$ DOC $>$ MBC. The DOC is an important $\mathrm{C}$ pool in soils and influences many chemical and biological processes (Chantigny, 2003) and may indicate shortterm responses to crop management practices. It generally decreases with depth due to retention by soil surfaces (Qualls and Haines, 1992). However, the contribution of crop residues and root exudates to the DOC pool is not entirely understood. Cropping systems have varying effects on soil $\mathrm{C}, \mathrm{N}$, and DOC pools by production of residues of variable quantity and quality (Lorenz and Lal, 2015). The MBC is a relatively small component of the SOM. It comprises only 1-3\% of total soil C. The MBC also considered as labile C, serves as a source (mineralization) or a sink (immobilization) of nutrient.

Zhu et al., (2014) also found that soil TOC and labile organic $\mathrm{C}$ fractions contents were significantly affected by straw returns, and were higher under straw return treatments than non-straw return at three depths. At 0-7 cm depth, soil MBC was significantly higher under plowing tillage than rotary tillage, but EOC was just opposite. Rotary tillage had significantly higher soil TOC than plowing tillage at 7-14 cm depth. However, at 14-21 cm depth, TOC, DOC and MBC were significantly higher under plowing tillage than rotary tillage except for EOC. The reason might be that rotary tillage and plowing tillage mixed crop straw into the deeper soil layer, making SOM well distributed at different depths Consequently, under shortterm condition, rice and wheat straw both return in rice-wheat rotation system could increase SOC content and improve soil quality.

Naresh et al., (2015a) also found that conservation tillage practices significantly influenced the total soil carbon (TC), total 
inorganic carbon (TIC), total soil organic carbon (SOC) and oxidizable organic carbon $(\mathrm{OC})$ content of the surface $(0$ to $15 \mathrm{~cm})$ soil. Wide raised beds transplanted rice and zero till wheat with $100 \%\left(\mathrm{~T}_{9}\right)$ or with $50 \%$ residue retention $\left(\mathrm{T}_{8}\right)$ showed significantly higher TC,SOC content of 11.93 and $10.73 \mathrm{~g} \mathrm{~kg}^{-1}$ in $\mathrm{T}_{9}$ and 10.98 and $9.38 \mathrm{gkg}^{-1}$, respectively in $\mathrm{T}_{8}$ as compared to the other treatments. Irrespective of residue incorporation/ retention, wide raised beds with zero till wheat enhanced $40.5,34.5,36.7$ and $34.6 \%$ of TIC, TC, SOC and OC in surface soil as compared to $\mathrm{CT}$ with transplanted rice cultivation. Aulakh et al., (2013) showed that PMN content after 2 years of the experiment in $0-5 \mathrm{~cm}$ soil layer of CT system, $\mathrm{T}_{2}, \mathrm{~T}_{3}$ and $\mathrm{T}_{4}$ treatments increased PMN content from $2.7 \mathrm{mgkg}^{-1} 7 \mathrm{~d}^{-1}$ in control $\left(\mathrm{T}_{1}\right)$ to $2.9,3.9$ and $5.1 \mathrm{mgkg}^{-1} 7 \mathrm{~d}^{-1}$ without $\mathrm{CR}$, and to $6.9,8.4$ and $9.7 \mathrm{mg} \mathrm{kg}^{-1} 7 \mathrm{~d}^{-1}$ with $\mathrm{CR}\left(\mathrm{T}_{6}, \mathrm{~T}_{7}\right.$ and $\left.\mathrm{T}_{8}\right)$, respectively. The corresponding increase of PMN content under CA system was from 3.6 $\mathrm{mgkg}^{-1} 7 \mathrm{~d}^{-1}$ in control to $3.9,5.1$ and 6.5 $\operatorname{mgkg}^{-1} 7 \mathrm{~d}^{-1}$ without CR and to 8.9, 10.3 and $12.1 \mathrm{mgkg}^{-1} 7 \mathrm{~d}^{-1}$ with CR. PMN, a measure of the soil capacity to supply mineral $\mathrm{N}$, constitutes an important measure of the soil health due to its strong relationship with the capability of soil to supply $\mathrm{N}$ for crop growth.

Mi et al., (2016) revealed that the TOC and $\mathrm{TN}$ concentrations were both highest in the upper $0-5 \mathrm{~cm}$ depth and then decreased with increasing depth. No significant differences in TOC were recorded between $\mathrm{CK}$ and $\mathrm{F}$ treatment at any of the four soil depths. However, addition of organic materials resulted in significant increases in TOC concentrations compared to the $\mathrm{CK}$, ranging from $16.0-29.5 \%$ in the $0-5 \mathrm{~cm}$ depth, and $18.3-28.9 \%$ in the $5-10 \mathrm{~cm}$ depth, respectively. Generally, no significant differences in TOC concentrations were observed between treatments at the deeper soil depth $(20-30 \mathrm{~cm})$. All fertilized treatments showed significant increases in soil $\mathrm{TN}$ in the $0-20 \mathrm{~cm}$ soil layer compared to the control. In comparison with NPK alone, the TN concentration in the FM treatment was $19.1 \%$ higher in the $0-5 \mathrm{~cm}$ depth, and increased by $5.9 \%, 12.7 \%$ and $7.6 \%$ in the FG, FM and FS treatments in the $5-10 \mathrm{~cm}$ depth, respectively.

Krishna et al., (2018) reported that the total organic carbon (TOC) allocated into different pools in order of very labile > less labile > non labile >labile, constituting about 41.4, $20.6,19.3$ and $18.7 \%$, respectively. In comparison with control, system receiving farmyard manure (FYM-10 Mg ha ${ }^{-1}$ season $^{1}$ ) alone showed greater $\mathrm{C}$ build up $(40.5 \%)$ followed by 100\% NPK+FYM (120:60:40 kg $\mathrm{N}, \mathrm{P}, \mathrm{K} \mathrm{ha}{ }^{-1}+5 \mathrm{Mg}$ FYM ha ${ }^{-1}$ season $^{-1}$ ) $(16.2 \%)$. In fact, a net depletion of carbon stock was observed with 50\% NPK $(-1.2 \mathrm{Mg}$ $\mathrm{ha}^{-1}$ ) and control $\left(-1.8 \mathrm{Mg} \mathrm{ha}^{-1}\right)$ treatments. Only $28.9 \%$ of $\mathrm{C}$ applied through FYM was stabilized as SOC. A minimal input of 2.34 $\mathrm{Mg} \mathrm{C} \mathrm{ha-} \mathrm{y}^{-1}$ is needed to maintain SOC level. The magnitude of carbon pools extracted under a gradient of oxidizing conditions was as follows: $\mathrm{C}_{\mathrm{VL}}>\mathrm{C}_{\mathrm{LL}}>\mathrm{C}_{\mathrm{NL}}>$ $\mathrm{C}_{\mathrm{L}}$ constituting about 41.4, 20.6, and 19.3 and $18.7 \%$, respectively, of the TOC. However, the contribution of $\mathrm{VL}, \mathrm{L}$ and $\mathrm{LL}$ pools to SOC was 51.2, 23.1 and $25.5 \%$, respectively. While active pool $\left(\mathrm{C}_{\mathrm{VL}}+\mathrm{C}_{\mathrm{L}}\right)$ constituted about $60.1 \%$, passive pool $\left(\mathrm{C}_{\mathrm{LL}}+\mathrm{C}_{\mathrm{NL}}\right)$ represented $39.9 \%$ of the TOC. Among the treatments, $\quad 100 \% \quad \mathrm{NPK}+\mathrm{FYM} \quad(44.4 \%)$ maintained a proportionately higher amount of soil $\mathrm{C}$ in passive pools. With an increase in the dose of fertilization, on average, $\mathrm{C}$ allocation into passive pool was increased (33.0, 35.3, $40.7 \%$ and $39.3 \%$ of TOC under control, 50\% NPK, $100 \%$ NPK and $150 \%$ NPK treatments, respectively).

Zheng et al., (2018) observed that the SOC storage in macro-aggregates under different 
treatments significantly decreased with soil depth. However, no significant variation was observed in the micro-aggregate associated $\mathrm{C}$ storage with depth. SOC storage increased with aggregate size from $1 \pm 2$ to $>2 \mathrm{~mm}$ and decreased with a decrease in aggregate size. The SOC storage in macro-aggregates of all sizes from $0-30 \mathrm{~cm}$ depth was higher in the ST treatment than in other treatments. From 30$60 \mathrm{~cm}$, trends were less clear. SOC storage in micro-aggregates showed the opposite trend, with significantly higher levels in the CT treatment from $0-30 \mathrm{~cm}$, and no significant differences between treatments below this depth. Kan et al., (2020) also found that compared with other treatments, NTS had the lowest values of $\mathrm{CO}_{2}-\mathrm{C}$ production across the four aggregate size classes in the $0-20 \mathrm{~cm}$ layers, which decreased by $33.5,26.7$, and $30.8 \%$ compared with RTS and by $32.6,30.5$, and $37.4 \%$ compared with CTS at $0-5,5-10$, and $10-20 \mathrm{~cm}$ layers, respectively. In addition, the CPM of the $\mathrm{LM}>2$ was dominant in the $20-50 \mathrm{~cm}$ layer, mainly due to the high size distribution of $\mathrm{LM}>2$ in the sub-soil with less disturbance.Macro-aggregates were the major pool of total potentially mineralization (TPM), accounting for 38.2-43.6\% (large) and $34.6-42.5 \%$ (small) of total mineralization, respectively. The TPM in the 0-30 cm layer increased from $1436.4 \mathrm{~kg} \mathrm{ha}^{-1}$ for NTS to $2013.9 \mathrm{~kg} \mathrm{ha}^{-1}$ for CTS. Such a trend can be explained that macro- aggregate size classes were predominately present for all tillage practices throughout the $0-50 \mathrm{~cm}$ layer in the bulk soil, accounting for 52.9$59.1 \%$ (large) and $24.6-28.0 \%$ (small) of size classes. Furthermore, the contribution of the surface layer to total $\mathrm{C}$ mineralization in the 0-30 $\mathrm{cm}$ layers increased with decrease in aggregate size. Such a trend further reflects the feature of aggregate size distribution, namely that the amount of macro-aggregate increases with increase in soil depths. Therefore, the difference in aggregate size distribution is the primary reason for the differences in mineralization per unit soil among the soil layers.

\section{Layer distribution of total mineralization}

Mineralization in soil science is the decomposition (i.e., oxidation) of the chemical compounds in organic matter, by which the nutrients in those compounds are released in soluble inorganic forms that may be available to plants (Beare et al., 1994). Mineralization is the opposite of immobilization. Mineralization increases the bioavailability of the nutrients that were in the decomposing organic compounds, most notably, because of their quantities, nitrogen, phosphorus, and sulfur. Whether the decomposition of an organic compound will result in mineralization or immobilization is dependent on its concentration proportionate to that of the carbon in the organic matter. If the concentration of a specific element exceeds the needs of the decomposer for biosynthesis or storage, then it will mineralize.

Sanderman et al., (2010) noted that changes in soil carbon obtained through the adoption of 'carbon friendly' management relative to more intensive management strategies ranged from 0.1 to $0.5 \mathrm{Mg} \mathrm{C} \mathrm{ha}^{-1}$ year $^{-1}$ over the 0 $15 \mathrm{~cm}$ soil layer. At a rate of change of 0.5 $\mathrm{Mg} \mathrm{C} \mathrm{ha}{ }^{-1}$ year $^{-1}$, it would take 3-4.5 years to detect a change in soil carbon content equivalent to $0.1 \%$ of the total $0-15 \mathrm{~cm}$ soil mass, depending on bulk density. If higher rates of carbon accumulation can be achieved, this time will decrease (e.g. for an increase of 2.0 Mg C ha year $^{-1}, 0.75-1.13$ years would be required). The implication of this observation is that, unless a management practice induces significant increases in soil carbon $\left(>0.3 \mathrm{Mg} \mathrm{C} \mathrm{ha}^{-1}\right.$ year $^{-1}$ for the $0-15$ $\mathrm{cm}$ layer or $>0.6 \mathrm{MgCha}^{-1}$ year $^{-1}$ for the $0-30$ $\mathrm{cm}$ layer), it will take $>5$ years to detect changes equivalent to $0.1 \%$ of the soil mass. 
Another implication is that the potential for detecting a change in soil carbon will increase as the thickness of the soil layer decreases. Given that carbon tends to accumulate to a greater extent near the soil surface, where an assessment of changes in SOC stocks for the 0-30 cm layer are required, a greater capability to detect change would exist where this layer is broken up into $0-10,10-20$, and 20-30 cm layers.

Fertilizer additions have often been shown to increase soil $\mathrm{C}$, which is primarily attributed to increased plant biomass production (Mazumder and Kuzyakov, 2010). However, fertilizer addition has also been shown to increase the rate of decomposition of SOM, especially in highly fertile soils, thereby depleting C content (Kirkby et al., 2013). Bell and Lawrence (2009) suggested that SOM cannot increase in low fertility soils unless the limiting nutrients such as $\mathrm{N}$ and $\mathrm{P}$ are added. Kirkby et al., (2014) also suggested that appropriate use of fertilizers in nutrient limited soils can enhance productivity and thus return more residues to the soil. The net effect of fertilizers on soil $\mathrm{C}$ depends on the productivity, $\mathrm{C}$ saturation and nature of the $\mathrm{C}$ pool. The loss in soil $\mathrm{C}$ observed with intensification mainly occurs from labile pools (Ghani et al., 2003), with implications for reduced retention of $\mathrm{N}$ and other nutrients in the soil, leading to lowered nutrient availability for plant uptake and greater losses to the environment.

Huggins et al., (2014) revealed that in addition to less $\mathrm{C}$ inputs than $\mathrm{CC}$, SS accelerated rates of SOC decomposition. Tillage effects on SOC were greatest in CC where CP had 26\% and NT 20\% more SOC than MP, whereas SOC in SS was similar across tillage treatments. Up to $33 \%$ of the greater SOC under $\mathrm{CC}$ for $\mathrm{CP}$ and NT, compared with MP, occurred below tillage operating depths. Jacinthe and Lal, (2009) concluded that the rates of $\mathrm{C}$ sequestration were estimated from the temporal trend in the recent SOC pool (0-40 $\mathrm{cm}$ in NR (23.2 $\mathrm{Mg} \mathrm{C}$ $\mathrm{ha}^{-1}$ ), 9-yr MP (32.9 Mg C ha ${ }^{-1}$ ) and 13-yr MP (33 $\mathrm{Mg} \mathrm{C} \mathrm{ha}^{-1}$ ), and ranged between 0.8 and $0.25 \mathrm{Mg} \mathrm{C} \mathrm{ha}{ }^{-1} \mathrm{yr}^{-1}$ during the first and second decades of restoration. Despite a similar amount of crop residue returned (2.8 $\mathrm{Mg} \mathrm{C} \mathrm{ha} \mathrm{yr}^{-1}$ ), recent SOC under 13-yr NT (36.8 $\mathrm{Mg} \mathrm{C} \mathrm{ha}{ }^{-1}$ ) exceeded that under 13-yr MP by $3.8 \mathrm{Mg} \mathrm{C} \mathrm{ha}^{-1}$. Saswat, (2014) found that Soil organic carbon status was seen declining with increase in soil depth. The average SOC amount was found to be 10.33, $8.73,7.19$ and $3.34 \mathrm{~g} \mathrm{~kg}^{-1}$ at soil depths of 0 $15 \mathrm{~cm}, 15-30 \mathrm{~cm}, 30-45 \mathrm{~cm}$ and $45-60 \mathrm{~cm}$ after harvest of the crop. Treatment $\mathrm{T}_{5}$ was found to have highest SOC in the upper most layer $11.80 \mathrm{~g} \mathrm{~kg}^{-1}$. Highest SOC stock and SOC sequestration rate were found in treatment $\mathrm{T}_{5}\left(46.29 \mathrm{t} \mathrm{ha}^{-1}\right.$ and $4.00 \mathrm{t} \mathrm{ha}^{-1}$ year $\left.{ }^{1}\right)$. Kan et al., (2020) observed that the contribution of soil layers to TPM differed among the aggregate size classes. For LM $>2$, the standardized coefficient of $20-30 \mathrm{~cm}$ soil layer was 0.47 , higher than those for $0-5,5-$ 10, and 10-20 cm layers. Thus, the contribution of surface layer to total $\mathrm{C}$ mineralization in the $0-30 \mathrm{~cm}$ layers increased with decrease in aggregate size classes. NTS decreases the total C mineralization due to the lower contribution of macro-aggregates, NTS versus RTS, CTS, and CT decreased TPM in the surface $30 \mathrm{~cm}$ layer across all aggregate size classes.

\section{Links between SOC sequestration and mineralization}

The amount of mineralisable organic matter in soil is an indicator of organic matter quality, acting as the interface between autotrophic and heterotrophic organisms during the nutrient cycling process (Gregorich et al., 1994). While potentially mineralisable $\mathrm{C}$ and $\mathrm{N}$ may be measured in both the field 
and laboratory, it is generally treated as a relative rather than an absolute value due to inconsistencies in methods (Haynes 2008). However, mineralisable organic matter may be a useful indicator to assess soil health under climate change, since it affects nutrient dynamics within single growing seasons, and may be used to compare management regimes and $\mathrm{C}$ sequestration over extended periods of time (Gregorich et al., 1994). Banger et al., (2010) revealed that compared to the control treatment, the increase in SOC was 36, 33, and $19 \%$ greater in organic, integrated, and NPK treatments. The much greater changes in water soluble $\mathrm{C}$ (WSC), microbial biomass $\mathrm{C}$ (MBC), light fraction of $\mathrm{C}$ (LFC), and particulate organic matter (POM) than SOC. Of the SOC, the proportion of POM was highest (24-35\%), which was followed by LFC (12- 14\%), MBC (4.6-6.6\%), and WSC $(0.6-0.8 \%)$. The application of fertilizers and/or FYM helps to sequester $\mathrm{C}$ in the soil and that can be used as indicators to determine the amount of $\mathrm{C}$ sequestered as a result of different management practices.

The significantly highest SOC content $(0.87 \%)$ was found in minimum tillage (MT) and three crop (rice, wheat and mung bean) residues retention combination whereas the lowest $0.44 \%$ SOC content was obtained in combined treatment of (deep tillage) DT with no crop residues retention. The increase of SOC might be due to slow decomposition of high amount of residue retained on soil under MT (Alam et al., 2014). The increase of N content in soil suggests $\mathrm{N}$-supplying capacity of soil which can be improved by returning straw to the soil and reducing tillage operation (Malhi et al., 2011). Adoption of reduced tillage, fertilization and crop diversity can increase organic $\mathrm{N}$ and mineralizable $\mathrm{N}$ stored in the soil (Das et al., 2016), thus improving soil fertility and nutrient supplying capacity of soil.
Wang et al., (2014) observed that at both the depositional and the eroding site, the $\mathrm{HF}$ represented the most important part ofthe total SOC at all depths, constituting $>80 \%$ of SOC. The contribution of the HF to SOC was slightly lower at the depositional site than at the eroding site at all depths, indicating the larger contribution of ALF and oLF to SOC at the depositional site. The relative contribution of fLF and oLF to SOC decreased with depth at both sites. No free and occluded light fractions were present at 160-200 $\mathrm{cm}$ depth at the eroding site. $\mathrm{Gu}$ et al., (2016) [revealed that SOC concentration in all treatments decreased with soil depth. The significant differences of SOC among treatments were solely at depths of 0-40 cm, where soil physicochemical properties changed. Further changes would have occurred following activity by microorganisms. Average SOC content at depths of $0-40 \mathrm{~cm}$ in ST and GT were $6.26 \mathrm{~g} \mathrm{~kg}^{-1}$ and $6.59 \mathrm{~g} \mathrm{Kg}^{-1}$ respectively, significantly higher than that of $5.44 \mathrm{~g} \mathrm{~kg}^{-1}$ in CK. The use of ST and GT increased SOC by $15.15 \%$ and $21.14 \%$ respectively. In the course of the growing season, SOC concentrations in all treatments presented substantial changes with seasons. The maximum SOC was recorded in the dry and cold season, and the minimum in the warm and wet season. Gu et al., (2016) also found that compared to the control without cover (CK), ST and GT treatments increased the contents of SOC,LOC, DOC, POC and EOC by $14.73 \%, 16.5 \%, 22.5 \%, 41.5 \%$ and $21 \%$, respectively, in the $0-40 \mathrm{~cm}$ soil layer, and by $17 \%, 14 \%, 19 \%$, and $30 \%$, respectively, in the $0-100 \mathrm{~cm}$ soil layer.

Kumar et al., (2018) also found that the ZTR (zero till with residue retention) $\left(\mathrm{T}_{1}\right)$ and RTR (Reduced till with residue retention) $\left(\mathrm{T}_{3}\right)$ showed significantly higher BC, WSOC, SOC and OC content of $24.5 \%, 21.9 \%, 19.37$ and $18.34 \mathrm{gkg}^{-1}$, respectively as compared to the other treatments. Irrespective of residue 
retention, wheat sown in zero till plots enhanced $22.7 \%, 15.7 \%, 36.9 \%$ and $28.8 \%$ of $\mathrm{BC}$, WSOC, SOC and OC, respectively, in surface soil as compared to conventional tillage. Simultaneously, residue retention in zero tillage caused an increment of $22.3 \%$, $14.0 \%, 24.1 \%$ and $19.4 \%$ in BC, WSOC, SOC and OC, respectively over the treatments with no residue management. Similar increasing trends of conservation practices on different forms of carbon under sub-surface $(15-30 \mathrm{~cm})$ soil were observed however, the magnitude was relatively lower. Kan et al., (2020) reported that the macro-aggregates (large and small) had lower mineralization quotient compared with micro-aggregates and silty clay, regardless of treatments and soil depths. The lowest value was recorded for NTS, especially for the $0-10 \mathrm{~cm}$ layer and for LM>2 in all five layers. Compared with the sub-soil layers, the $0-10 \mathrm{~cm}$ layer had a higher correlation coefficient and reached a significant level. These results indicate that straw retention decreases the mineralization quotient by comparing the differences between CTS and CT, which maybe the reason for the higher SOC concentration under straw retention. In general, SOC concentrations decline with increase in soil depths, and a lack of fresh crop straw input results in lower SOC stocks in the sub-soil layers.

In conclusion, the conservation tillage (ST and NT) treatments effectively improved the soil structure and strengthened the stability of water-stable soil aggregates. In addition, they increased the SOC content and storage in aggregates of different sizes with comparison of MP and CT. Furthermore, long-term adoption of conservation tillage methods significantly increased the content of waterstable macro-aggregates and of aggregate MWD, and increased the SOC content, ratio of, and storage in the macro-aggregates. In particular, the ST treatment increased the
SOC content and enriched the newly formed $\mathrm{C}$ in macro-aggregates. In addition, correlation analysis suggested a significant correlation between SOC and aggregateassociated $\mathrm{C}$ in differently sized aggregates. The $0.25-1$ and $1-2 \mathrm{~mm}$ aggregates were the main sites of SOC storage and were also the important indices of the soil $\mathrm{C}$ pool saturation. Changes in SOC concentration and composition occurred along with changes in structural stability to a depth of $15 \mathrm{~cm}$, consistent with a reduced capacity for tilled soil to physically protect organic matter from decomposition. Although differences in stability were evident from $15-28 \mathrm{~cm}$, no significant difference in SOC concentration was observed among the land uses, indicating that increased aggregate stability is not always linked to an increase in SOC storage.

In topsoil, WS macro-aggregate formation was highest $(28.2 \mathrm{~g}$ of $>250 \mathrm{~mm}$ aggregates per gram of $\mathrm{C}$ added) with the lowest residue input $\left(2.5 \mathrm{~g}\right.$ residue-C $\mathrm{kg}^{-1}$ soil). In the subsoil, WS macro-aggregate formation increased to $76.3 \mathrm{~g}$ of $>250 \mathrm{~mm}$ aggregates per gram of $\mathrm{C}$ added with residue input of $5 \mathrm{~g}$ residue-C $\mathrm{kg}^{-1}$ soil and decreased thereafter. The concentration of POC, MBC and HWC were higher under topsoil $(0-10 \mathrm{~cm})$ as compared to subsoil $(10-20 \mathrm{~cm})$ in CA practices. Organic carbon concentrations in the <0.053-, 0.053- to 0.25-, 0.25- to 2.0, and $>2.0-\mathrm{mm}$ fractions were $14.0,12.0,14.4$, $24.1 \%$ greater, respectively, in $\mathrm{CA}$ than in $\mathrm{CF}$. The contents of SOC,LOC, DOC, POC and EOC by $14.73 \%, 16.5 \%, 22.5 \%, 41.5 \%$ and $21 \%$ in the $0-40 \mathrm{~cm}$ soil layer, and by $17 \%$, $14 \%, 19 \%$, and $30 \%$ in the $0-100 \mathrm{~cm}$ soil layer. These results suggest that over time, the MBC and MBC-derived $\mathrm{C}$ under the finesized residue treatment may constitute a significant source of stable SOC through strong physical and chemical bonding to the mineral soil matrix. Conservation management in the North West IGP is 
important in maintaining soil structure stability and conserving SOC from rapid decomposition with associated organic carbon fractions. The NTS had a positive effect on upper soil macro-aggregate formation, and thus increased SOC concentration and decreased SOC mineralization. Thus, the application of NTS enhances SOC sequestration by promoting macro-aggregate formation and decreasing mineralization quotient.

\section{References}

Alam, M.K., Islam, M.M., Salahin, N. and Hasanuzzaman, M. 2014 Effect of Tillage Practices on Soil Properties and Crop Productivity in Wheat-Mungbean-Rice Cropping System under Subtropical Climatic Conditions. The Sci World J. 110.

Arai, M., Miura, T., Tsuzura, H., Minamiya, Y., Kaneko, N., 2018. Two-year responses of earthworm abundance, soil aggregates, and soil carbon to no-tillage and fertilization. Geoderma 332: 135-141.

Aulakh MS, Garg Ashok K, Kumar Shrvan.2013. Impact of Integrated Nutrient, Crop Residue and Tillage Management on Soil Aggregates and Organic Matter Fractions in Semiarid Subtropical Soil under Soybean-Wheat Rotation. Am. J Plant Sci. 4:2148-2164.

Awale R, Chatterjee A, David Franzen. 2013. Tillage and $\mathrm{N}$-fertilizer influences on selected organic carbon fractions in a North Dakota silty clay soil. Soil Tillage Res. 134:213-222.

Awanish K. 2016. Impact of conservation agriculture on nutrient dynamics in dominant cropping systems in a black soil of central India.Ph.D. Thesis, Indira Gandhi Krishi Vishwavidyalaya Raipur, Chhattisgarh.

Bandyopadhyay PK, Saha S, Mani PK, Mandal B.2010. Effect of organic inputs on aggregate associated organic carbon concentration under long-term rice-wheat cropping system. Geoderma.154:379-386.
Banger KGS, Toor GS, Biswas A, Sidhu SS, Sudhir K. 2010. Soil organic carbon fractions after 16-years of applications of fertilizers and organic manure in a Typic Rhodalfs in semi-arid tropics. Nutr Cycl Agroecosyst. 86:391-399.

Beare MH, Hendrix PF, Coleman DC.1994. Water-stable aggregates and organic matter fractions in conventional tillage and no-tillage soils. Soil Sci. Soc. Am. J. 58:777-786.

Beli M, Lawrence D.2009. Soil carbon sequestration-myths and mysteries. The Department of Primary Industries and Fisheries, Queensland Government, Australia.

Benbi DK, Senapati N. 2010. Soil aggregation and carbon and nitrogen stabilization in relation to residue and manure application in rice-wheat system in northwest India. Nutr. Cycl. Agroecosyst. 87:233-247

Chantigny MH.2003. Dissolved and waterextractable organic matter in soils: a review on the influence of land use and management practices. Geoderma. 113:357-380.

Chen HQ, Hou RX, Gong YS, Li HW, Fan MS, Kuzyakov Y.2009. Effects of 11 years of conservation tillage on soil organic matter fractions in wheat monoculture in Loess Plateau of China. Soil Tillage Res. 106:85-94.

Dameni, H., Wang, J., and Qin, L. 2010. Soil Aggregate and Organic Carbon Stability under Different Land Uses in the North China Plain. Commu Soil Sci Plant Anal, 41(9): $1144-1157$

Das Bappa, Chakraborty D, Singh VK, Ahmed M, Singh AK, Barman A. 2016. Evaluating fertilization effects on soil physical properties using a soil quality index in an intensive rice-wheat cropping system. Pedosphere. 26 (6):887-894.

Dey,A., Dwivedi, B.S.,Bhattacharyya, R., Datta,S.P., Meena, M.C., Das, T.K., and Singh, V.K. 2016. Conservation Agriculture in a Rice-Wheat Cropping System on an Alluvial Soil of NorthWestern Indo-Gangetic Plains: Effect on Soil Carbon and Nitrogen Pools. J. Indian Soc Soil Sci. 64 (3): 246-254 
Dikgwatlhe SB, Chen Z, Lal R, Zhang H, Chen F. 2014. Changes in soil organic carbon and nitrogen as affected by tillage and residue management under wheat-maize cropping system in the North China Plain. Soil Tillage Res. 144:110-118

Dong W, Hu C, Chen S, Zhang Y.2009. Tillage and residue management effects on soil carbon and $\mathrm{CO}_{2}$ emission in a wheat-corn double-cropping system. Nut. Cycl. Agro. Ecosyst. 83:27-37.

Du Z, Ren T, Hu C. 2010. Tillage and residue removal effects on soil carbon and nitrogen storage in the North China Plain. Soil Sci Soc Am J. 74:196-202

Du, Z.L., Ren, T.S., Hu, C.S., Zhang, Q.Z., and Humberto, B.C. 2013. Soil aggregate stability and aggregate associated carbon under different tillage systems in the north China plain. J Integr Agric. 12:2114-23.

Fang, X.M., Chen, F.S., Wan, S.Z., Yang, Q.P., and Shi, J.M. 2015. Topsoil and Deep Soil Organic Carbon Concentration and Stability Vary with Aggregate Size and Vegetation Type in Subtropical China. PLOS ONE 10(9): e0139380.doi:10.1371/journal.pone.0139 380

Gal, A.; Vyn, T.J.; Micheli, E.; Kladivko, E.J.; McFee, W.W.2007. Soil carbon and nitrogen accumulation with long-term notill versus moldboard plowing overestimated with tilled-zone sampling depths. Soil Tillage Res. 96: 42-51

Ghani A, Dexter M, Perrott KW.2003. Hot-water extractable carbon in soils: a sensitive measurement for determining impacts of fertilization, grazing and cultivation. Soil Bio Biochem. 35:1231-1243.

Ghosh BN et al. 2018. Effects of fertilization on soil aggregation, carbon distribution and carbon management index of maize-wheat rotation in the north-western Indian Himalayas. Ecological Indicators, https://doi.org/10.1016/j.ecolind.2018.02. 050

Gonzalez-Sanchez, E.J., Ordonez-Fernandez, R., Carbonell- Bojollo, R., Veroz-Gonzalez, O., Gil- Ribes, J.A. 2012. Meta-analysis on atmospheric carbon capture in Spain through the use of conservation agriculture. Soil Tillage Res. 122: 52-60.

Govaerts, B.; Verhulst, N.; Sayre, K.D.; Dixon, J.; Dendooven, L. 2009. Conservation agriculture and soil carbon sequestration; Between myth and farmer reality. Crit. Rev. Plant Sci. 28: 97-122

Gregorich EG, Carter MR, Angers DA, Monreal CM, Ellert BH. 1994. towards a minimum data set to assess soil organic matter quality in agricultural soils. Can J Soil Sci.74:367-385.

Guan S, Dou S, Chen G, Wang G, Zhu J. 2015. Isotopic characterization of sequestration and transformation of plant residue carbon in relation to soil aggregation dynamics. Appl Soil Ecol. 96:18-24

Guo L-J, Lin S, Liu T-Q, Cao C-G, Li C-F. 2016. Effects of Conservation Tillage on Topsoil Microbial Metabolic Characteristics and Organic Carbon within Aggregates under a Rice (Oryza sativa L.) -Wheat (Triticum aestivum L.) Cropping System in Central China. PLoS ONE 11(1): e0146145. https://doi.org/10.1371/journal.pone.0146 145

Gupta Choudhury, S., Srivastava, S., Singh, R., Chaudhari, S.K., Sharma, D.K., Singh, S.K., and Sarkar, D. 2014. Tillage and residue management effects on soil aggregation, organic carbon dynamics and yield attribute in rice-wheat cropping system under reclaimed sodic soil. Soil Tillage Res, 136, 76- 83.

Häring V, Manka'abusi D, Akoto-Danso EK, Werner S, Atiah K, Steiner C et al., 2017. Effects of biochar, waste water irrigation and fertilization on soil properties in West African urban agriculture. Sci. Rep, 7:10738 DOI:10.1038/s41598-017-10718$\mathrm{y}$

Haynes RJ. 2008. Soil organic matter quality and the size and activity of the microbial biomass: their significance to the quality of agricultural soils. In: Huang Q, Huang PM, Violante A (eds) Soil mineralmicrobe-organic interactions: theories and applications. Springer, Berlin, 201-230.

Huang, S., Sun, Y.N., Rui, W.Y., Liu, W.R., and Zhang, W.J. 2010. Long-term effect of no-tillage on soil organic carbon fractions 
in a continuous maize cropping system of northeast China. Pedosphere.20:285-92.

Huggins, D.R., Allmaras, R.R., Clapp, C.E., Lamb, J.A., and Randall, G.W. 2014. Corn-Soybean Sequence and Tillage Effects on Soil Carbon Dynamics and Storage. Soil Sci. Soc. Am. J. 71(1): 145154.

Jacinthe. P.A., and Lal, R. 2009. Tillage Effects on Carbon Sequestration and Microbial Biomass in Reclaimed Farmland Soils of South western Indian. Soil Sci. Soc. Am. J. 73: 605-613.

Jat, H.S., Ashim Datta, P. C. Sharma, Virender Kumar, A. K. Yadav, Madhu Choudhary, Vishu Choudhary, M. K. Gathala, D. K. Sharma, M. L. Jat, N. P. S. Yaduvanshi, Gurbachan Singh and A. McDonald. 2018. Assessing soil properties and nutrient availability under conservation agriculture practices in a reclaimed sodic soil in cereal-based systems of NorthWest India, Arch Agron Soil Sci, 64 (4): 531-545

Jat, R.K., Sapkota, T.B., Singh, R.G., Jat, M.L.L., Kumar, M., and Gupta, R.K. 2014. Seven years of conservation agriculture in a rice-wheat rotation of Eastern Gangetic Plains of South Asia: yield trends and economic profitability. Field Crops Res. 164: 199-210.

Jiang, X., Wright, A. L., Wang, J. and Li, Z. 2011. Long-term tillage effects on the distribution patterns of microbial biomass and activities within soil aggregates. Catena 87: 276-280.

Kan, Z.R., Virk, A.L., Wu, G., Qi, J.Y., Ma, S.T., Wang, X., Zhao, X., Lal, R., Zhang, H.L., 2019. Priming effect intensity of soil organic carbon mineralization under notill and residue retention. Appl. Soil Ecol. https://doi.org/10.1016/j.apsoil.2019.1034 45.

Kirkby CA, Richardson AE, Wade LJ, Passioura J.B., Batten GD, Blanchard C, Kirkegaard JA. 2014. Nutrient availability limits carbon sequestration in arable soils. Soil Bio Biochem. 68:402-409.

Krishna, C. A., Majumder, S.P., Padhan, D., Badole, S., Datta,A., Mandal, B., and Gade, K.R. 2018. Carbon dynamics, potential and cost of carbon sequestration in double rice cropping system in semiarid southern India. J. Soil Sci Plant Nutri, 18 (2): 418-434

Kumar, M., Kundu, D.K., Ghorai, A.K., Mitra, S., Singh, S.R., 2018. Carbon and nitrogen mineralization kinetics as influenced by diversified cropping systems and residue incorporation in Inceptisols of eastern Indo-Gangetic Plain. Soil Tillage Res. 178:108-117.

Kumar,V., Naresh, R.K., Satendra Kumar, Sumit Kumar, Sunil Kumar, Vivak, Singh, S.P., and Mahajan, N.C. 2018. Tillage, crop residue, and nitrogen levels on dynamics of soil labile organic carbon fractions, productivity and grain quality of wheat crop in Typic Ustochrept soil. J.Pharmacog Phytochem. 7(1): 598-609.

Liu, C., Lu, M., Cui, J., Li, B., Fang, C.M. 2014. Effects of straw carbon input on carbon dynamics in agricultural soils: a metaanalysis. Global Change Biol. 20 (5):1366-1381.

Lorenz K. and Lal R.2015. Managing soil carbon stocks to enhance the resilience of urban ecosystems. Carbon Management. 6:3550.

Malhi, S., Nyborg, M., Goddard, T.W., and Puurvee, D. 2011. Long-term tillage, straw and $\mathrm{N}$ rate effects on some chemical properties in two contrasting soil types in Western Canada. Nutrient Cycl Agroecosyst. 90(1):133-146

Mazumder B, Kuzyakov Y. 2010. Effect of fertilization on decomposition of ${ }^{14} \mathrm{C}$ labeled plant residues and their incorporation into aggregates. Soil Tillage Res. 109:94-102.

Mi Wenhai, Lianghuan Wu, Philip C, Brookes Yanling, Liua Xuan, Zhanga Xin, Yang. 2016. Changes in soil organic carbon fractions under integrated management systems in a low-productivity paddy soil given different organic amendments and chemical fertilizers. Soil Tillage Res. 163:64-70.

Mikutta R, Kleber M, Torn MS, Jahn R. 2006. Stabilization of soil organic matter: association with minerals or chemical recalcitrance? Biogeochem. 77: 25-56 
Naresh RK, Timsina J, Bhaskar S, Gupta RK, Singh AK, Dhaliwal SS, et al., 2017. Effects of Tillage, Residue and Nutrient Management on Soil Organic Carbon Dynamics and its Fractions, Soil Aggregate Stability and Soil Carbon Sequestration: A Review. EC Nutrition. (12) 2:53-80

Naresh, R.K., Gupta, Raj K., Gajendra Pal, Dhaliwal, S.S, Kumar, Dipender, Kumar Vineet, Arya, Vichitra Kumar, Raju, Singh, S.P., Basharullah and Singh, Onkar. 2015a.Tillage crop establishment strategies and soil fertility management: resource use efficiencies and soil carbon sequestration in a rice-wheat cropping system. Eco. Env. \& Cons. 21:127-134

Naresh, R.K., Gupta, Raj K., Singh, S.P. Dhaliwal, S.S., Ashish Dwivedi, Onkar Singh, Vikrant Singh, and Rathore, R.S. 2016.Tillage, irrigation levels and rice straw mulches effects on wheat productivity, soil aggregates and soil organic carbon dynamics after rice in sandy loam soils of subtropical climatic conditions. J Pure Appl MicrobioI, 10(2): 1061-1080.

Naresh, R.K., Jat, P.C., Kumar, V., Singh, S.P., and Kumar, Y. 2018. Carbon and nitrogen dynamics, carbon sequestration and energy saving in soils under different tillage, stubble mulching and fertilizer management in rice-wheat cropping system. J. Pharmacog Phytochem. 7(6): 723-740.

Naresh,R.K., Arvind Kumar, Bhaskar,S., Dhaliwal, S.S., Vivek, Satendra Kumar, Sunil Kumar and Gupta, R.K. 2017. Organic matter fractions and soil carbon sequestration after 15- years of integrated nutrient management and tillage systems in an annual double cropping system in northern India. J.Pharmacog Phytochem. 6(6): 670-683.

Ou, H.P., Liu, X.H., Chen, Q.S., Huang, Y.F., He, M.J.,Tan, H.W., Xu, F.L., Li, Y.R., and Gu M.H. 2016. Water-Stable Aggregates and Associated Carbon in a Subtropical Rice Soil under Variable Tillage. Rev Bras Cienc Solo. v40:e0150145.

Qualls RG, Haines BL. 1992. Measuring adsorption isotherms using continuous, unsaturated flow through intact soil cores. Soil Sci. Soc. Am. J. 56:456-460.

Rabbi, S.M.F., Wilson, B.R., Lockwood, P.V., Daniel, H., Young, I.M. 2014. Soil organic carbon mineralization rates in aggregates under contrasting land uses.Geoderma 216: 10-18.

Sainju, U.M.; Senwo, Z.N.; Nyakatawa, E.Z.; Tazisong, I.A.; Reddy, K.C. 2008. Soil carbon and nitrogen sequestration as affected by long-term tillage, cropping systems, and nitrogen fertilizer sources. Agric. Ecosyst. Environ. 127: 234-240.

Samal, S.K., Rao, K.K., Poonia, S.P., Kumar, R.,Mishra, J.S., Ved Prakash, Mondal, S., Dwivedi, S.K., Bhatt, B.P., Naik, S.K.,Choubey, A.K.,Kumar, V., Malik, R.K., and Mc Donald, A. 2017. Evaluation of long-term conservation agriculture and crop intensification in rice-wheat rotation of Indo-Gangetic Plains of South Asia: Carbon dynamics and productivity. Eur J Agron. 90: 198208

Sarker, J.R., Singh, B.P., Cowie, A.L., Fang, Y.Y., Collins, D., Badgery, W., Dalal, R.C.2018a. Agricultural management practices impacted carbon and nutrient concentrations in soil aggregates, with minimal influence on aggregate stability and total carbon and nutrient stocks in contrasting soils. Soil Tillage Res. 178: 209-223.

Sarker, J.R., Singh, B.P., Cowie, A.L., Fang, Y.Y., Collins, D., Dougherty, W.J., Singh, B.K. 2018b. Carbon and nutrient mineralisation dynamics in aggregate-size classes from different tillage systems after input of canola and wheat residues. Soil Biol. Biochem.116: 22-38.

Saswat P. Estimation of crop productivity and soil organic carbon stock dynamics in organically grown rice-rice sequence. $\mathrm{M}$. Sc. (Ag) Thesis, Orissa University of Agriculture \& Technology, 2014, Bhubneswar-751003

Sheng H, Zhou P, Zhang Y, Kuzyakov Y, Zhou Q, Ge T, Wang C. 2015. Loss of labile organic carbon from subsoil due to landuse changes in subtropical China. Soil 
Biol. Biochemist. 88:148-157.

Six J, Elliott ET, Paustian K, Doran JW. 1998. Aggregation and soil organic matter accumulation in cultivated and native grassland soils. Soil Sci. Soc. Am. J. 62: 1367-1377

Somasundaram, J., Chaudhary, R.S., Kumar, D.A., Biswas, A.K., Sinha, N.K., Mohanty, M., Hati, K.M., Jha, P., Sankar, M., Patra, A.K., Dalal, R., Chaudhari, S.K. 2018. Effect of contrasting tillage and cropping systems on soil aggregation, carbon pools and aggregate- associated carbon in rainfed Vertisols. Eur. J. Soil Sci. 69 (5): 879-891.

Song, K., Yang, J.J., Xue, Y., Lv, W.G., Zheng, X.Q., Pan, J.J. 2016. Influence of tillage practices and straw incorporation on soil aggregates, organic carbon, and crop yields in a rice-wheat rotation system. Sci. Rep. 6: 36602. https://doi.org/10.1038/srep36602.

Triberti L, Nastri A, Giordani G, Comellini F, Baldoni G, Toderi G. 2008. Can mineral and organic fertilization help sequestrate carbon dioxide in cropland? Eur J Agron. 29:13-20

Wang, Q.; Lu, C.; Li, H.; He, J.; Sarker, K.K.; Rasaily, R.G.; Liang, Z.; Qiao, X.; Li, H.; Mchugh, A.D. 2014. The effects of notillage with subsoiling on soil properties and maize yield: 12-Year experiment on alkaline soils of Northeast China. Soil Tillage Res. 137: 43-49
Wang, X., Qi, J.Y., Zhang, X.Z., Li, S.S., Virk, A.L., Zhao, X., Xiao, X.P., Zhang, H.L., 2019. Effects of tillage and residue management on soil aggregates and associated carbon storage in a double paddy cropping system. Soil Tillage Res. 194,104339. https://doi.org/10.1016/j. still. 2019.104339.

Xie, J., Peng, B., Wang, R., Batbayar, J., Hoogmoed, M., Yan, Y., Zhang, S., Yang, X., and Sun, B. 2018. Responses of crop productivity and physical protection of organic carbon by macro-aggregates to long-term fertilization of an Anthrosol. Eur. J. Soil Sci.69: 555-567

Yan Y, Xie J, Sheng H, Chen G, Li X, Yang Z. 2013 The impact of land use/ cover change on storage and quality of soil organic carbon in mid subtropical mountainous area of southern China. J. Geographi Sci.19:49-57

Zheng, H., Liu, W., Zheng, J., Luo, Y., Li, R., Wang, H., et al., 2018. Effect of longterm tillage on soil aggregates and aggregate associated carbon in black soil of Northeast China. PLoS ONE 13 (6): e0199523.

Zhu L, Hu N, Yang M, Zhan X, Zhang Z.2014. Effects of Different Tillage and Straw Return on Soil Organic Carbon in a RiceWheat Rotation System. PLoS ONE. 9(2):e88900. doi: 10.1371/journal. pone. 0088900

\section{How to cite this article:}

Shipra Yadav, R. K. Naresh, Yogesh Kumar and Yadav, R. B. 2020. Conservation Tillage and Fertilization Impact on Carbon Sequestration and Mineralization in Soil Aggregates in the North West IGP under an Irrigated Rice-Wheat Rotation: A Review. Int.J.Curr.Microbiol.App.Sci. 9(02): 592-611. doi: https://doi.org/10.20546/ijcmas.2020.902.074 